\title{
Cave Colinas Pedra - Piraquara/Paraná (Brasil)
}

\author{
Vander Valduga ${ }^{1, a}$ y Ari Pinto Portugal ${ }^{2, b}$ \\ ${ }^{1}$ Doctor en Geografia. Maestría em Turismo - UFPR, Curitiba, Paraná, Brasil \\ ${ }^{2}$ Economista, Propietario - Cave Colinas de Pedra, Piraquara, Paraná, Brasil
}

\begin{abstract}
Resumen. El presente trabajo analiza el contexto de la creación y la concepción del proyecto de Cave Colinas de Pedra y su proceso de regeneración del patrimonio ferroviario. Se hace una contextualización de la vitivinicultura en Paraná y posteriormente presenta una síntesis histórica de la vía férrea de Brasil, al analizar brevemente algunos factores que se produjeron en el curso de este modelo de transportes en el país, hasta su completa de la decadencia, en mediados del Siglo XX. Como metodología, se utilizó la investigación bibliográfica y visitas in loco, así como encuestas con el propietario de la empresa. Como consideraciones, presenta la relevancia del proyecto en la situación turística brasileña y apunta para la necesidad de conservación y revitalización del patrimonio ferroviario del país, el cual, en la actualidad, se está utilizando parcialmente con fines turísticos.
\end{abstract}

\section{Introducción}

En 2012 la producción de uvas en Brasil fue de 1.455.809 toneladas en un área sembrada de 82.507 hectáreas. El Estado de Rio Grande del Sur es el más grande productor con 840.251 toneladas y el Estado del Paraná es el quinto de Brasil en producción, con 70.500 toneladas de uvas. El destaque de la producción brasileña son los vinos espumosos, con su consumo en gran expansión, en el orden del $10 \%$ al año, mientras que vinos tintos y blancos tienen una reducción gradual de consumo y producción [1].

La vitivinicultura en el Paraná se remite al siglo XVI, introducida por los jesuitas españoles que, después de la destrucción de las misiones jesuíticas por los bandeirantes, fue extinguida. Solamente, en el siglo XIX hay la reanudación de vitivinicultura con la introducción de esquejes traídos de São Paulo y sembradas en los alrededores de Curitiba, capital de la Provincia. En los primeros años del siglo $\mathrm{XX}$, los inmigrantes italianos introdujeron la vitivinicultura, de esta vez más cercana la frontera de la Provincia de Santa Catarina y a partir de 1940 se da inicio a una importante producción en la ciudad de Londrina, región norte de Paraná, en un sector donde cafetales fueron diezmados por los frecuentes heladas.

A partir de los años cuarenta, con el crecimiento de la importancia de vitivinicultura en Paraná, el Ministerio de Agricultura creó una Estación Experimental de Viticultura y de Enología, en el pueblo de Campo Largo, en la Región Metropolitana de Curitiba. Sin embargo, a partir de los años sesenta lo vitivinicultura sufrió una decadencia en esta región por la infestación de los viñedos con la perla de tierra, que prácticamente diezmó los viñedos. En los años setenta la vitivinicultura ocupó de nuevo el espacio en el norte del Estado, a partir de una colonia japonesa, con el objetivo de la producción de uvas de mesa. La implantación de vitis viníferas se produjo en esta región

\footnotetext{
a e-mail: vandervalduga@gmail.com

b e-mail: colinasdepedra@gmail.com
}

a partir de 1989 con el inicio de la producción de vinos finos.

El las vinícolas concentradas sobre la región metropolitana de Curitiba y que producen vinos finos y espumosos, prácticamente en casi su totalidad importan uvas del estado de Rio Grande del Sul y, muchas veces, importan los productos listos, comercializando a partir del Estado del Paraná.

Esta breve introducción inicial contempla contextualizar, aunque de forma reducida, de vitivinicultura brasileña y del Estado del Paraná. El caso presentado en este breve estudio se sitúa en la población de Piraquara, en la región metropolitana de Curitiba, de Estado del Paraná, como el mapa 1.

En este emprendimiento, llamada de Cave Colinas de Pedra, elementos de la vitivinicultura se han añadido al patrimonio industrial ferroviario local, volviéndose el emprendimiento un importante caso para que se estudie. Sin embargo, antes de avanzar en los detalles del estudio, de que tiene por objeto informar el patrimonio ferroviario y lo vitivinicultura, convergiendo en el caso de estudios Cave Colinas de Pedra, se hace necesario contextualizar la situación ferroviaria de Brasil y el Estado del Paraná.

\subsection{La ferrovía en Brasil}

El primer tramo ferroviario del país unía Porto Mauá, al fondo de la Bahía de Guanabara al Fragoso en Rio de Janeiro y tenía una extensión de 14.5 kilómetros. Pasados unos años, la vía férrea transpuso la Sierra del Mar y llegó a Petrópolis. La inauguración de primera vía férrea en Brasil, que nombrada "Estrada de Ferro Mauá", ocurrió en un contexto político donde el imperio intentaba consolidarse como una nación unificada e independiente con relación a Portugal. Con la prohibición del tráfico negrero, se liberaron capitales financieros para inversiones en sectores que prácticamente inexistían. En la década

This is an Open Access article distributed under the terms of the Creative Commons Attribution License 4.0, which permits unrestricted use, distribution, and reproduction in any medium, provided the original work is properly cited. 


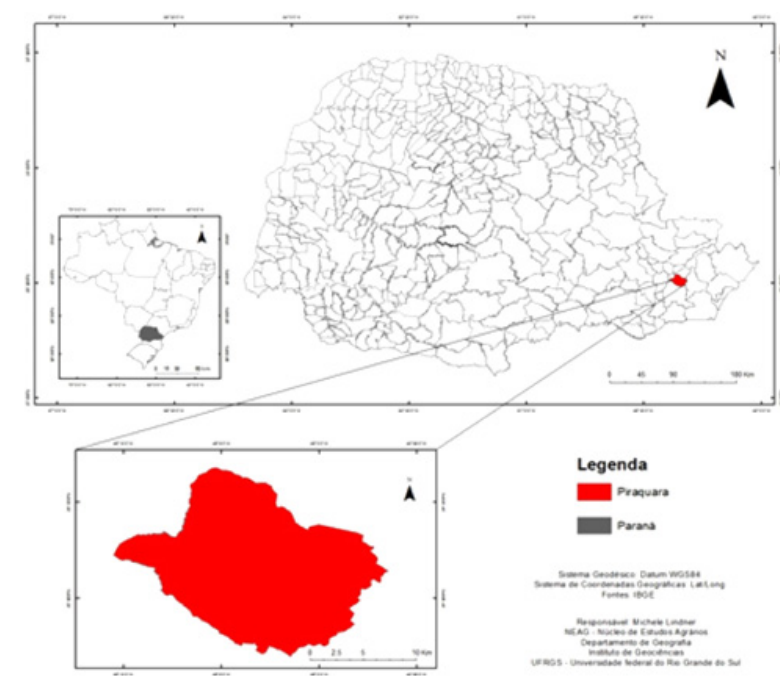

Mapa 1. Localización de Piraquara, Paraná, Brasil. Fuente: Michele Lindner/ NEAG/UFRGS.

de 1860 se crearon 08 ferrocarriles, además de bancos, empresas de minería, entre otras cosas. Las inversiones en vías férreas fueron realizadas por concesiones, que se volvieron una característica de la política de infraestructura del imperio con el fin de atraer inversiones y que, al mismo tiempo, volvió impracticable que se estableciera de una red nacional de vías férreas. Las inversiones en ferrocarriles las hicieron, sobre todo, los británicos [2].

En la segunda mitad del siglo XIX el eje de mayor desarrollo ferroviario brasileño fue Rio de Janeiro - São Paulo, con destaque la expansión económica de São Paulo. El ciclo del café proporcionó la extensión de ferrocarriles de São Paulo, interconectando ciudades de la región y permitiendo la conexión con otros Estados, tales como Minas Gerais y Espirito Santo. En paralelo, otros Estados como Pernambuco, Bahia, Rio Grande Norte y Paraíba, al noreste y en Paraná, Santa Catarina y Rio Grande del Sul, en la región meridional de Brasil también desarrollaron el sistema ferrocarril. De la total inexistencia de vías férreas hasta el final del imperio en 1889 , el país pasa a tener 9.583 kilómetros de vías que fueron establecidas por 62 empresas en 12 provincias, con predominio de capital privado [3]. El 2 de febrero de 1885 se inauguró el tramo inicial de la vía férrea Paranaguá - Curitiba, con 110.915 kilómetros de extensión. A lo largo de su trazado, se construyeron a "distintas obras de arte" de considerable ingeniería, entre ellas, 13 túneles, el más grande con 429 metros de largo; 28 puentes metálicos de 8 a 50 metros de vano y 4 viaductos. La osadía técnica para la época se demostró por la transposición de la montaña, a partir del kilómetro 45, que caracteriza la Vía Férrea de Paraná como los más difíciles que se construyeron en el mundo. La vía férrea parte de 15.6 metros de altitud en Paranaguá, en el litoral, y alcanza Curitiba en la meseta, a 952 metros de altitud. La vía férrea se dividió en tres sesiones distintas: 1) Paranaguá a Morretes, con $42 \mathrm{~km}, 2$ ) Morretes a Roça Nova, con 38 km y, 3) Roça Nova a Curitiba, con $30 \mathrm{~km}$. A partir de la Proclamación de la República en 1889 otros tramos del ferrocarril se inauguraron en Paraná y el tramo del principal, esto es, Paranaguá, pasando por Curitiba y en llegando a Ponta Grossa alcanzó 306 kilómetros de extensión.

En Brasil, actualmente, existen 33 trenes turísticos según el Ministerio de Turismo, sin embargo, no sirven solamente al turismo, pero participan de la conservación de la memoria de las poblaciones que viven en el entorno. Los trenes turísticos y sus estaciones son testigos de la historia, de la evolución económica, política y social de una localidad. Las locomotoras y las estaciones de ferrocarriles son representaciones del pasado y fundamentales para el valor patrimonial. De todo lo que ha permanecido de las vías férreas brasileñas, menos del $10 \%$ se utiliza para el turismo [4]. Entre las vías férreas que se utilizan para el turismo, tiene prominencia en Brasil el paseo de Tren Curitiba - Paranaguá, realizado a partir de la vía férrea Paranaguá - Curitiba, inaugurada en 1885. El tren transporta alrededor a de 200 mil de personas al año con 110 kilómetros de extensión. El paseo pasa por más de 30 puentes en medio Sierra del Mar, un importante bioma brasileño. Además de los puentes, 13 túneles componen el paseo. Uno de los túneles, de número 13 se desactivó en 1969, debido a la electrificación de parte del intervalo de la vía férrea, exigiendo la construcción de otro túnel paralelo con mayores dimensiones. Estos túneles están ubicados cerca de la Estación de trenes Roça Nova, en Piraquara. En 1997 se privatizó esta vía férrea.

Piraquara es un pueblo de la región metropolitana de Curitiba que tiene $101 \mathrm{mil}$ de habitantes en $227.560 \mathrm{~km}^{2}$. La población de Curitiba, en la región metropolitana, es de 3.168.000 de habitantes, en un área de $15.419 \mathrm{~km}^{2}$ y Piraquara está a 22 kilómetros del capital Curitiba. La región concentra un $64 \%$ de la población urbana del Estado y el Producto interior bruto es de 74.8 mil millones de reales. Piraquara tiene más de un $85 \%$ de su territorio localizado en sector de protección medioambiental y es responsable de $50 \%$ del suministro de agua de la región metropolitana de Curitiba. Además la ciudad concentra un centenar de yacimientos del Río Iguazú, que forman las Cascadas del Iguazú, en el parque nacional Iguazú, patrimonio natural de la UNESCO. Debido a las condiciones de conservación medioambiental, la ciudad tiene muchas restricciones industriales y su economía se basa en el comercio y los servicios.

En 2000, don Ari Portugal, director jubilado de HSBC Seguro, adquirió en una subasta, el túnel desactivado, el de $\mathrm{n}^{0} 13$, juntamente con la Estación de Trenes de Roça Nova, en la ocasión esta se encontraba en estado precario.Antes de adquirir el túnel de tren y la estación, adquirió un área al entorno de 45 hectáreas. Toda la propiedad está dentro de un área de conservación medioambiental y declarado patrimonio natural de Sierra del Mar, regulado por un decreto del estado. Según el propietario, él no tenía ninguna pretensión económica inicial con la adquisición. Su intención era la conservación del patrimonio medioambiental y ferroviario.

Tras algunos años, investigaciones y contactos con profesionales del vino, el propietario descubrió que el túnel presentaba condiciones convenientes para la maduración de vino espumoso. A partir de ese momento, se cerró el túnel en las dos entradas, y por dos años consecutivos se han realizado de las pruebas diarias de temperatura y 


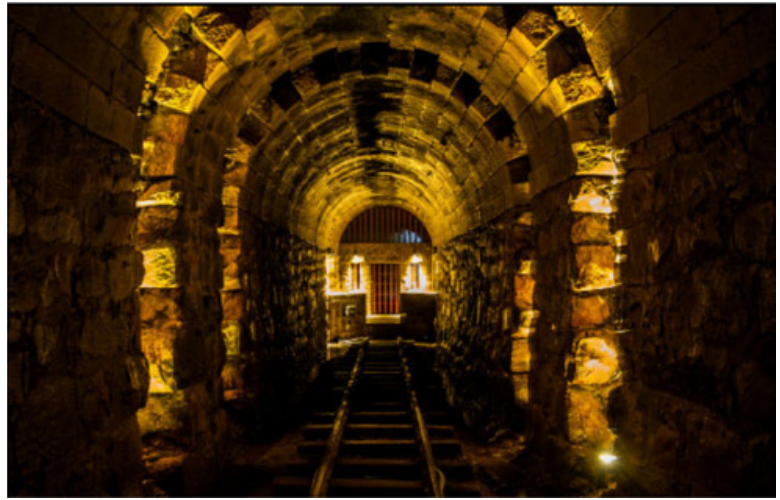

Imagen 1. Entrada principal del túnel. Acervo de los autores.

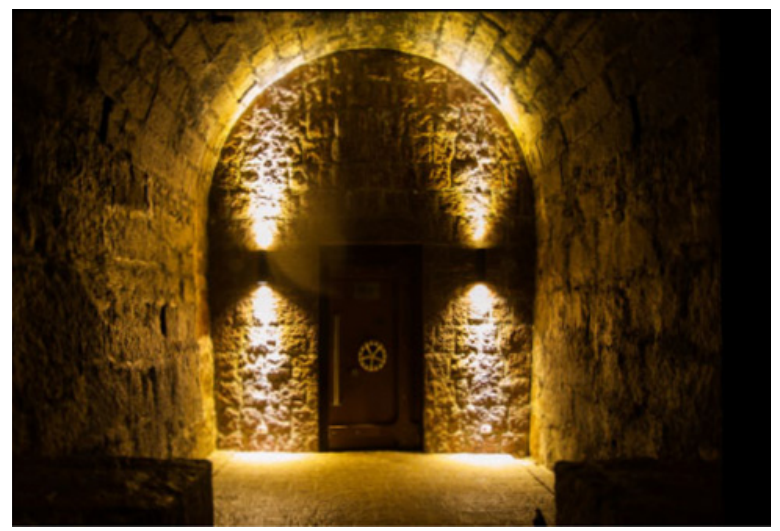

Imagen 2. Puerta de entrada de la cave de maduración. Acervo de los autores.

la humedad. Al final de este período, se ha constatado que la temperatura variaba solamente $1{ }^{\circ} \mathrm{C}$ a lo largo de todo el año, siendo $16^{\circ} \mathrm{C}$ en el invierno y en el máximo $17^{\circ} \mathrm{C}$ en el verano y la humedad relativa del aire en $85 \%$.

A partir de ese momento, el propietario ha buscado asociaciones para desarrollar la elaboración de espumantes, y ha proyectado un complejo turístico con el fin de valorar el patrimonio medioambiental y ferroviario del local, con el objetivo de abrir las puertas al público para que la población pueda conocer esta parte de la historia ferroviaria del país. La imagen 1 muestra a entrada del túnel.

El túnel tiene la extensión de 429 metros, con 5 metros de largo y 3,5 metros de ancho. La imagen 2 muestra la puerta de la entrada de la cave de maduración y finalización del espumante.

La excavación del túnel se hizo para transponer una montaña en roca de granito, en una altitud de 952 metros. El centro del túnel es 65 metros abajo del punto el más alto de la montaña. Al destinarse a la estructuración de un producto turístico, el túnel ha sido restaurado y se ha dividido en tres partes: 1) la primera, con 154 metros se recorre en un coche eléctrico/ferroviario, transporta hasta 15 personas, este llega hasta el medio del túnel, donde se localiza la bodega; 2) segundo, con 92 metros alberga el espacio de maduración, el dégorgement y la conclusión del vino espumoso y, 3) la tercera con 132 metros, aún se encuentra en estado original, pero que se puede restaurarla

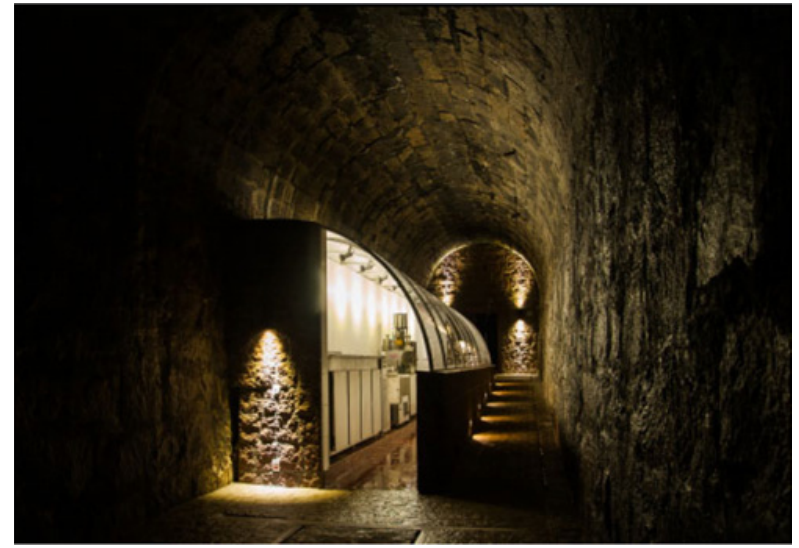

Imagen 3. Espacio para dégorgement. Acervo de los autores.

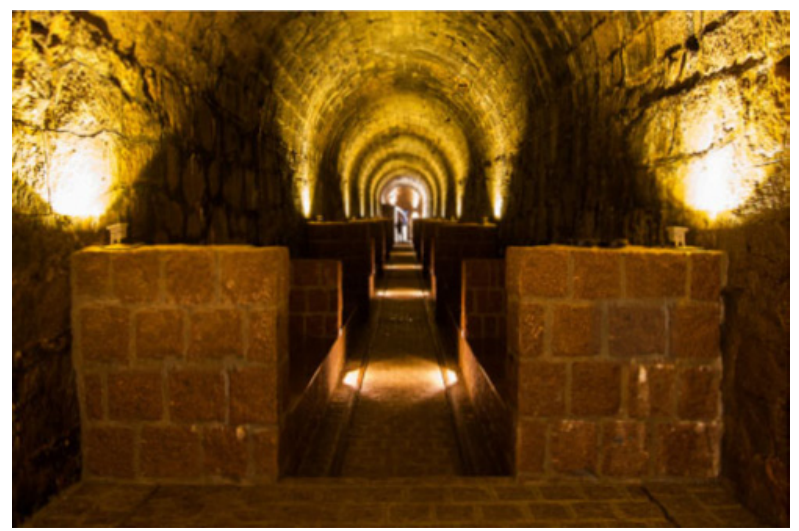

Imagen 4. Caves de maduración. Acervo de los autores.

según la demanda de los espumantes. Otros 29 metros permanecen en la salida del túnel después de segunda puerta. Las imágenes 3 y 4 enumeran el interior de la bodega.

Las dos puertas internas, en el espacio de la bodega, son puertas modelo "caja fuerte", ambas de alta resistencia. La capacidad de almacenamiento inicial es de 50.000 botellas, pero si la segunda parte del túnel se restaure, la capacidad puede llegar a 1 (uno) millón de botellas.

La Cave Colinas de Pedra solamente hará la maduración del vino espumoso, dejando las levaduras en autolisis por el método de elaboración de champenoise, dégordement, y procesos finales. La primera etapa de la elaboración del espumante se hará por la tradicional vinícola brasileña, Cave Geisse, localizada en Pinto Bandeira, en el Estado de Rio Grande del Sul - de Brasil, de propiedad del respetado enólogo chileno, del don Mário Geisse, que fue también, del enólogo jefe de la M. Chandon en Brasil y es enólogo jefe de la Casa Silva, una vinícola Chilena. Por lo tanto, se elaborará primera etapa del espumante en Rio Grande del Sul y la segunda, en el túnel de Cave Colinas de Pedra. El flujo de circulación se pensó para tener visitación turístico, con aislamiento de la parte del proceso, por a la seguridad.

Junto al túnel, hace parte de la propiedad la Estación de Trenes de Roça Nova, que ha sido edificada en 1885. Cuando la compraron en 2000, estaba en deterioro y ha 


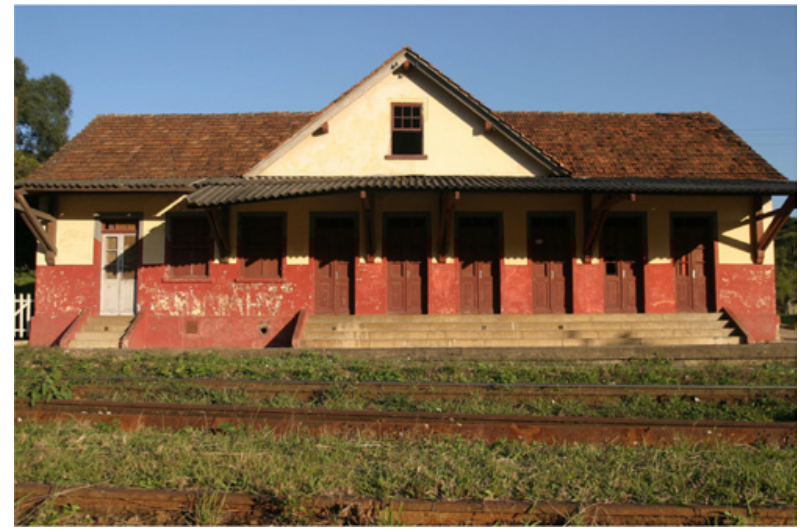

Imagen 5. Estación Roça Nova en 2000. Acervo de los autores.

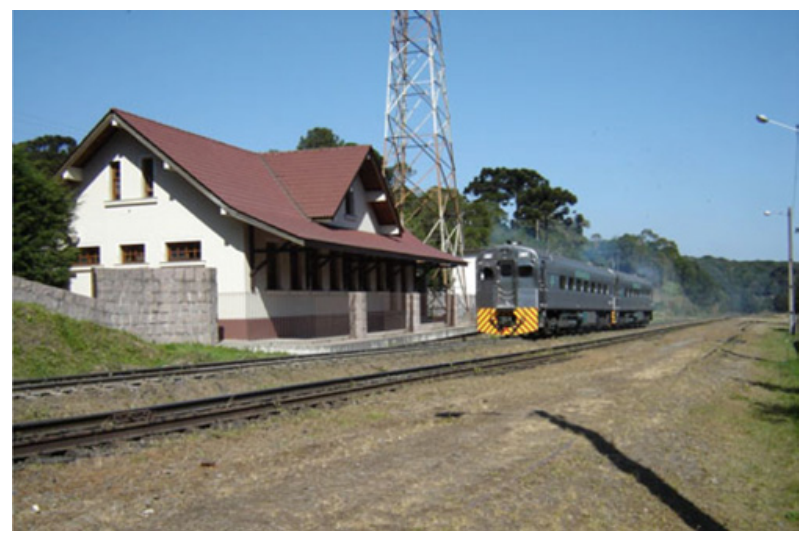

Imagen 6. Estación Roça Nova, 2014. Acervo de los autores.

sido totalmente restaurada según el proyecto original, a partir de investigaciones y apoyo de la Coordinación de Patrimonio Histórico del Estado de Paraná. Las imágenes 5 y 6 enseñan la estación en 2000 y el edificio actual, después del restauro.

En la estación funcionará un restaurante de alta gastronomía, con capacidad para 60 lugares, con la utilización de productos orgánicos y regionales. Albergará aún una tienda de vinos espumantes, espacio para degustación, encuentros profesionales, cofradías, pequeñas celebraciones y otras actividades.

En la propiedad hay también una un vagón de lujo, que en Brasil de lo denomina litorina, este ha sido adaptado para servir chocolates y espumantes y ha sido nombrado "Choco Champ". Esta litorina fue construida en Philadelphia - EE.UU., en la década de 1960. La misma ha sido restaurada a los moldes de la original, con capacidad para 20 personas y hace parte de la decoración del ambiente, es decir, no está en condiciones de circular o hacer paseos. Las imágenes 9 y 10 enseñan las características externas e internas de la Littorina "Choco Champ".

Los raíles existentes en el local, han sido transformados en postes y cercan parte de la propiedad, componiendo el escenario. Según el propietario, hay un proyecto previsto para la construcción de 10 pequeños bungalós, con arquitectura de estación de trenes existentes a lo largo de la vía férrea, y que se transformarán en

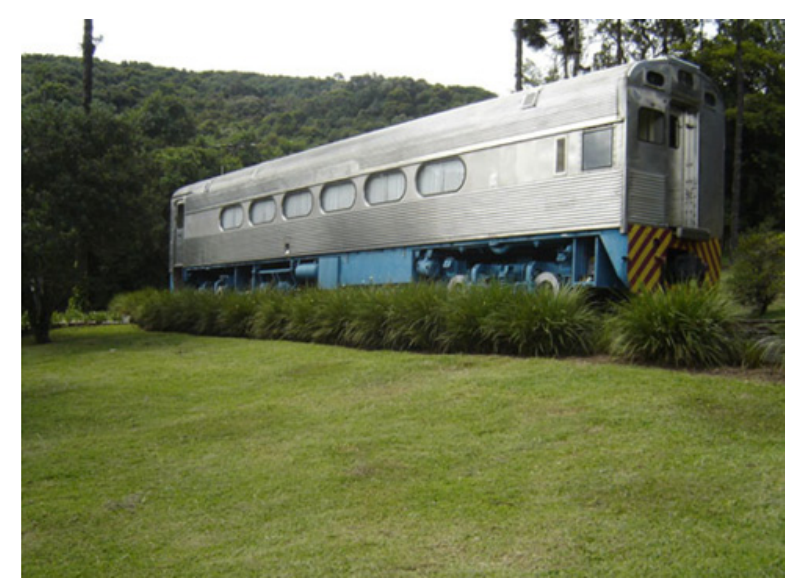

Imagen 7. Litorina, vista externa. Acervo dos autores.

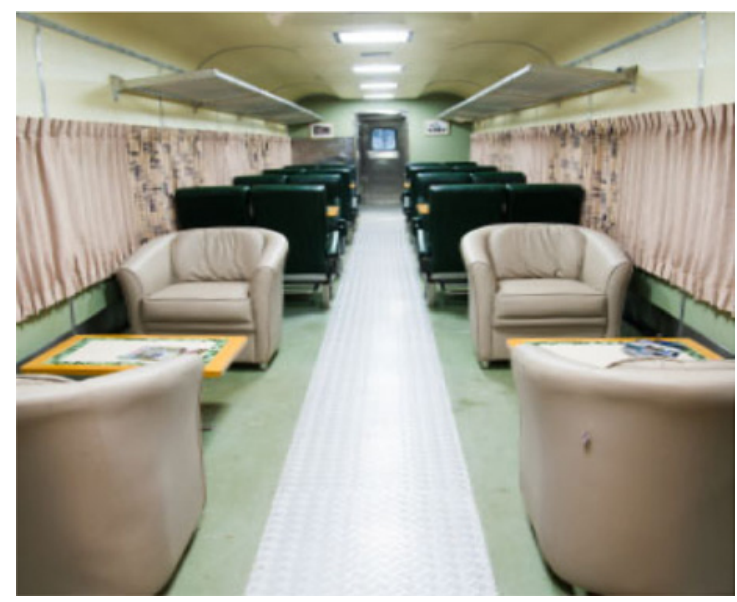

Imagen 8. Litorina, vista interna. Acervo de los autores.

posadas. Habrá aún, un espacio para celebraciones con capacidad de 300 personas.

A lo que se refiere a la participación desde la perspectiva turística, algunos paseos en tren, en el trayecto de Curitiba - Paranaguá, podrán parar en la Estación de Tren de Roça Nova y las personas podrán conocer al túnel y a la propiedad, y hacer u tentempié o incluso comidas, entre otras actividades como picnic al aire libre. También se ha establecido una colaboración con agentes y operadores de turismo con el objetivo de llevar al público al local. Se ofrecerá transporte a los visitantes en autobús y furgonetas, entre la región metropolitana de Curitiba hasta el local. Diferentes acciones están planificadas, en el sentido de unir la perspectiva de la producción de espumantes con el patrimonio ferroviario, asociando los productos gastronómicos y todo lo que se asocie a ello.

\section{Consideraciones finales}

La revitalización del patrimonio industrial ferroviarios en Brasil es urgente, hay muchos sectores completamente deteriorados y abandonados por la falta de interés del Estado en invertir en la memoria ferroviaria de Brasil y, también, por la opción brasileña por el transporte en carreteras. No fuera por esta iniciativa, la Estación Roça 
Nova estaría completamente abandonada y destruida y el túnel podría caer en el olvido, formando parte de los distintos mecanismos de olvido sostenidos por el estado brasileño. La concesión y venta de áreas es una alternativa para la revitalización de estos espacios, pero que, por otra parte, si así convertidos en propiedades particulares, pueden privar las personas de conocerlos. Afortunadamente, en ese caso, hay total interés del propietario en abrir las puertas para que las personas descubran un poco de la memoria ferroviaria de Brasil, añadiendo otro producto al escenario, en el caso el vino espumoso, la belleza natural y los ingredientes regionales.

\section{Referencias}

[1] V. R. Botelho, E. J. Pires, II Enc. Frut. Campos Gerais. Viticultura como opção de desenvolvimento para os Campos Gerais. UEPG, v. 1, p. 40-54, (2009)

[2] IPHAN., Inventário das Estações. Pat. Fer. no RS, v. 1. 1874-1959, (2002)

[3] A. J. Mamede, L. G. Vieira, A. P. Santos, Cad. Vir. de Tur. Trens turísticos e patrimônio cultural: como o turismo ferroviário tem resgatado, preservado e valorizado o patrimônio cultural., v. 8, $\mathrm{n}^{\circ}$ 2. (2008)

[4] R. F. Schoppa, 150 anos do trem no Brasil, Votorantim, (2004) 